\title{
Transcriptional factor Nrf2 is essential for aggresome formation during proteasome inhibition
}

\author{
SIYUE QIN ${ }^{1-3}$, CHANGAN JIANG ${ }^{2,3}$ and $\mathrm{JU} \mathrm{GAO}^{2-4}$ \\ ${ }^{1}$ Department of Neurobiology, Shandong Provincial Key Laboratory of Mental Disorders, \\ School of Medicine, Shandong University, Jinan, Shandong 250012; ${ }^{2}$ Key Laboratory of Obstetrics, \\ Gynecologic and Pediatric Diseases and Birth Defects, Ministry of Education; \\ ${ }^{3}$ Department of Pediatrics, West China Second University Hospital, Sichuan University, Chengdu, Sichuan 610065; \\ ${ }^{4}$ The United Innovation of Mengchao Hepatobiliary Technology Key Laboratory of Fujian Province, \\ Mengchao Hepatobiliary Hospital of Fujian Medical University, Fuzhou, Fujian 350002, P.R. China
}

Received February 11, 2019; Accepted September 18, 2019

DOI: $10.3892 /$ br.2019.1247

\begin{abstract}
Aggrephagy, the aggresome-related protein degradation system, represents a protective cellular response to shuttle misfolded proteins into the microtubule-organizing center for degradation through the autophagic pathway during stress conditions, including heat shock, oxidative stress and proteasome inhibition. In response to proteasome failure, many genes are transcriptionally activated to facilitate ubiquitinated proteins to be cleared via the aggrephagy pathway. Although many regulators involved in aggresome formation have been identified, the mechanism how transcriptional activation promotes aggresome formation remains unknown. Here, we have demonstrated that nuclear factor erythroid 2-related factor 2 (Nrf2) accumulated in the nucleus and activated the transcription of sequestosome-1 (p62) during proteasome inhibition in 293 cells. Loss of Nrf2 resulted in failure of aggresome formation and cell death; whereas overexpression of p62 alleviated Nrf2 knockdown-induced aggresome formation defects and promoted cell survival. Notably, blocking Nrf2 activation using a p38/MAPK inhibitor prevented proteasome inhibitor-induced aggresome formation. These findings suggested that Nrf2 may be a critical regulator of aggresome formation, which protects cells from proteasome dysfunction-induced stress.
\end{abstract}

Correspondence to: Dr Ju Gao or Professor Changan Jiang, Department of Pediatrics, West China Second University Hospital, Sichuan University, 24 South Section, 1 Yihuan Road, Chengdu, Sichuan 610065, P.R. China

E-mail: jugao204@gmail.com

E-mail: ca.jiang@siat.ac.cn

Key words: nuclear factor erythroid 2-related factor 2, transcription, p62, aggresome, p38/MAPK

\section{Introduction}

The term aggresome refers to a stress sensitive subcellular structure, containing misfolded proteins, heat-shock proteins (HSPs) and proteasomal components, and it is formed when the protein-degradation system is overwhelmed (1). Aggresome formation requires an intact microtubule system and the distinct presence of $\gamma$-tubulin (2-4), which ultimately terminates in lysosomal degradation $(5,6)$. Therefore, the aggresome pathway likely provides a backup system for delivery of aggregated proteins from the cytoplasm to lysosomes for degradation (4). Various stress conditions, including oxidative stress (7), proteasome inhibition (3) and heat shock (8), induce aggresome formation through different molecular mechanisms. In response to failure of ubiquitin proteasome system (UPS),p62 assembles the polyubiquitinated proteins into microaggregates through binding to their ubiquitin chains with its $\mathrm{C}$-terminal ubiquitin binding domain and oligomerizing at its $\mathrm{N}$-terminal PB1 domain (9). These microaggregates are then recognized by histone deacetylase 6 (HDAC6) and retrogradely transported via the microtubule network to the microtubule-organizing center for aggresome formation $(3,10)$. Hence, proteasome inhibition-induced aggresome formation represents a highly organized biological process to switch polyubiquitinated proteins from the UPS to the autophagy pathway.

The aggrephagy pathway alleviates proteasome proteolysis failure-induced cell death under various stress conditions (5). Loss of aggresome formation regulators, such as p62, HDAC6 or PTEN-induced kinase 1 (PINK1), causes apoptosis in various cell types during proteasome inhibition $(3,11,12)$. Consistently, toxicity of aggregated proteins is strongly enhanced by inhibition of the microtubule-dependent transport machineries, which are required for microaggregate transportation (4). More importantly, Parkinson's disease associated proteins, such as $\alpha$-synuclein, leucine rich repeat kinase 2 and mutant DJ1, have been reported to be degraded via aggrephagy, suggesting that abnormalities in this backup protein degradation system may cause neurodegeneration (13-15). However, the mechanism underlying the activation of this compensatory pathway and the cellular factors that regulate aggresome formation remain unknown. 
Transcriptional control of stress-responsive genes is a crucial part of the cell response to a wide variety of stresses (16). In response to oxidative stress, nuclear factor erythroid 2-related factor 2 (Nrf2), encoded by the NFE2L2 gene, binds to the antioxidant response elements (ARE) sequence within the promoter of detoxifying and antioxidant enzymes and activates their transcription (17). Interestingly, the induction of p62 by oxidative stress is mediated by Nrf2 and, at the same time, p62 competitively binds to Kelch-like ECH-associated protein 1 (Keap1) to activate Nrf2 (18-20). Although Nrf2 and p62 are essential for the oxidative stress response, the function of Nrf2 in aggresome formation during proteasome inhibition has not been determined.

Here, we showed that the loss of Nrf2 impaired aggresome formation and caused a hypersensitivity to proteasome inhibition in stressed cells, which was restored by the overexpression of p62. This study established Nrf2 as a major transcriptional mediator for proteasome stress-induced activation of the aggresome-autophagy pathway.

\section{Materials and methods}

Plasmid construction. The human Nrf2 and p62 full-length cDNA was obtained from Addgene, Inc. Nrf2 cDNA was amplified by Phusion high-fidelity DNA polymerase (Thermo Fischer Scientific, Inc.). A total of 30 cycles of PCR amplification were performed $\left(98^{\circ} \mathrm{C}\right.$ for $5 \mathrm{sec}, 55^{\circ} \mathrm{C}$ for $5 \mathrm{sec}$ and $72^{\circ} \mathrm{C}$ for $\left.90 \mathrm{sec}\right) . \mathrm{PCR}$ products were digested by BamHI and $X b a \mathrm{I}$. The digested fragment was cloned into pTango-CFlag vector (BioAtom Technology) linearized with BamHI/XbaI. The resulting construct is further referred to as Flag-Nrf2.p62 was amplified by PCR as described above $\left(30\right.$ cycles of $98^{\circ} \mathrm{C}$ for $5 \mathrm{sec}, 55^{\circ} \mathrm{C}$ for $5 \mathrm{sec}$ and $72^{\circ} \mathrm{C}$ for $80 \mathrm{sec}$ ) and cloned into pTango-NFlag (BioAtom Technology) after digestion with $E c o$ RI and $X b a \mathrm{I}$. The resulting construct is further referred to as Flag-p62. The human p62 promoter $(-1781 /+46)$ was obtained from genomic DNA purified from 293 cells based using publicly available sequence data (https:/www.ncbi.nlm. nih.gov/gene/8878). Two fragments, namely the p62/SQSTM promoter (PCR, 30 cycles of $98^{\circ} \mathrm{C}$ for $5 \mathrm{sec}, 55^{\circ} \mathrm{C}$ for $5 \mathrm{sec}$ and $72^{\circ} \mathrm{C}$ for $40 \mathrm{sec}$ ) digested by $\mathrm{BamHI} / E c o \mathrm{RI}$ and the enhanced (E) GFP (PCR, 30 cycles of $98^{\circ} \mathrm{C}$ for $5 \mathrm{sec}, 55^{\circ} \mathrm{C}$ for $5 \mathrm{sec}$ and $72^{\circ} \mathrm{C}$ for $30 \mathrm{sec}$ ) digested by $E c o \mathrm{RI} / \mathrm{XbaI}$, were cloned into an BamHI/XbaI-digested pBluescript II vector (Addgene, Inc.). The resulting construct was a fused EGFP sequence downstream of the p62 promoter region. All constructs were confirmed by sequencing. Detailed information for the primers is presented in Table SI.

Cell lines and reagents. MG132, anisomycin (ANI), actinomycin D (ActD), TAK715 and N-acetyl-cysteine were obtained from Tocris Bioscience. 293 cells were obtained from the American Type Culture Collection and were cultured in DMEM (Gibco; Thermo Fischer Scientific, Inc.) with $10 \%$ heat-inactivated fetal bovine serum (FBS; Gibco; Thermo Fischer Scientific, Inc.) and 1\% penicillin/streptomycin (Gibco; Thermo Fischer Scientific, Inc.) at $37^{\circ} \mathrm{C}$ with $5 \% \mathrm{CO}_{2}$.

For the chemical treatment, 50,000 cells were cultured for $24 \mathrm{~h}$ before treatment in 24 -well plates at $80 \%$ confluence. Change the medium containing MG132 (2 $\mu \mathrm{M})$, ANI
$(5 \mu \mathrm{g} / \mathrm{ml}), \operatorname{ActD}(2 \mu \mathrm{g} / \mathrm{ml}), \operatorname{MG} 132(2 \mu \mathrm{M})+$ ANI $(5 \mu \mathrm{g} / \mathrm{ml})$, MG132 $(2 \mu \mathrm{M})+\operatorname{ActD}(2 \mu \mathrm{g} / \mathrm{ml}), \operatorname{MG} 132(2 \mu \mathrm{M})+$ TAK715 $(10 \mu \mathrm{M})$ or MG132 $(2 \mu \mathrm{M})+\mathrm{N}$-acetyl-cysteine $(1 \mathrm{mM})$ and treat for $12 \mathrm{~h}$. In time-dependent experiments, 293 cells were cultured in MG132 $(2 \mu \mathrm{M})$-containing medium for $12 \mathrm{~h}$ and ANI $(5 \mu \mathrm{g} / \mathrm{ml})$ was added at $0,2,4$ or $6 \mathrm{~h}$. To evaluate dose dependent effects of MG132 on Nrf2 accumulation, 293 cells were treated with $0.1,0.5,1,2$ and $10 \mu \mathrm{M} \mathrm{MG132}$ for $12 \mathrm{~h}$.

Transient transfection of 293 cells was performed using Mega-tran 1.0 (OriGene Technologies, Inc.) according to the manufacturer's instructions. Briefly, 50,000 cells were plated in 24-well plates $24 \mathrm{~h}$ prior to transfection ( $80 \%$ confluence). Medium was replaced with $0.5 \mathrm{ml}$ of complete medium containing FBS and antibiotics $1 \mathrm{~h}$ before transfection. DNA $(0.5 \mu \mathrm{g})$ was diluted in $50 \mu \mathrm{l}$ of serum-free DMEM, mixed and $1.5 \mu \mathrm{l}$ of MegaTran 1.0 was added and gently mixed. The resulting solution was incubated for $15 \mathrm{~min}$ at room temperature and added to the cells. Medium was replaced $5 \mathrm{~h}$ after adding the transfection solution. Transfection efficiency was checked $24 \mathrm{~h}$ post transfection by western blot.

Generation of Nrf2 knockout (nrf2-/-) cells. Nrf2 knockout cells were generated from 293 cells with a CRISPR/Cas9 system designed in our lab. pSpCas9(BB)-2A-Puro (PX459) V2.0 was a gift (cat. no. 62988; Addgene, Inc.) (21). All single guide (sg) RNA targeting sequences were predicted as first hits using the CRISPR guide design website (https://benchling. com). The 293 cells were first transfected with two PX459 vectors, which targeted 5'-CTTTTTTTGTCTTAAACAT-3' and 5'-GAAAGTTATGGCAGGTTTA-3', to delete the first exons of the NFE2L2 gene. After $24 \mathrm{~h}$, cells were diluted and seeded in 96-well plates at 1 cell/well to isolate monoclonal cells without Nrf2 expression, as determined by quantitative (q) PCR and western blot analysis. Genomic DNA was extracted from cells by using PureLink Genomic DNA kit (Invitrogen; Thermo Fischer Scientific, Inc.). Further PCR analysis (as above; 30 cycles of $98^{\circ} \mathrm{C}$ for $5 \mathrm{sec}, 55^{\circ} \mathrm{C}$ for $5 \mathrm{sec}$ and $72^{\circ} \mathrm{C}$ for $30 \mathrm{sec}$ ) was performed to validate the deletion of exon 2 of the NFE2L2 gene in the monoclonal cells; primer sequences are presented in Table SI.

Generation of stable expression cells. The coding sequences Flag-p62 and Flag-Nrf2 were cloned into the plenti6-LVP lentiviral vectors (Thermo Fischer Scientific, Inc.). Viruses were generated and used to transduce $n r f 2^{-/-}$cells as described previously (12). Briefly, plenti6-Flag-p62 and plenti6-Flag-Nrf2 plasmids were co-transfected with lentiviral packaging mix into 293 cells using Mega-tran 1.0. Supernatant containing lentivirus was harvested and cellular debris was removed by centrifugation (500 x g, $10 \mathrm{~min}$, room temperature). A total of $10,000 \mathrm{nrf} 2^{-/-}$cells was added to 24 -well plates and transduced at an MOI of 5. Three days after transduction, puromycin ( $2 \mu \mathrm{g} / \mathrm{ml}$ ) was added to the culture medium to generate stable $n r f 2^{-/-}\left[\right.$Flag-Nrf2] and $n r f 2^{-/}$[Flag-p62] cell lines. After puromycin selection, single cell clones were verified by qPCR analysis to validate the expression of exogenous Nrf2 and p62. Transfection controls were prepared with empty vector (plenti6-LVP). To evaluate the aggresome formation efficiency, $n r f 2^{+/+}, n r f 2^{-/-}$[Vector], [nrf2 $2^{-/-}$[Flag-Nrf2] and $n r f 2^{-/-}$[Flag-p62] cells were treated with MG132 $(2 \mu \mathrm{M})$ for $14 \mathrm{~h}$. 
Cell death assay. Cell death-inducing effects of proteasomal inhibition were measured with CF488A-Annexin V (ANXA5) and propidium iodide (PI) Apoptosis kits (cat. no. 30061; Biotium, Inc.) as described previously (12). A total of 100,000 cells $/ \mathrm{cm}^{2}$ were grown in $10 \mathrm{~cm}$ dishes. After $24 \mathrm{~h}$, they were treated with DMSO $(0.1 \%)$ or $2 \mu \mathrm{M}$ MG132 (in DMSO) for $20 \mathrm{~h}$. Cells were then harvested by digestion with $0.05 \%$ trypsin-EDTA, washed twice with ANXA5-Binding buffer and resuspended in $100 \mu \mathrm{l}$ of this buffer. To each sample, $15 \mu \mathrm{l} \mathrm{CF488A-ANXA5} \mathrm{and} 5 \mu \mathrm{l}$ PI were added and incubated in the dark for $30 \mathrm{~min}$ at room temperature. Unbound dyes were washed off with binding buffer, cells were mounted onto slides. All and images were captured using a fluorescence microscope (magnification, $\mathrm{x} 40$ ).

$R N A$ extraction and reverse transcription-quantitative $(R T-q)$ $P C R$. Total RNA was extracted from cells using the Qiagen All-Prep DNA/RNA/miRNA Universal kit (Qiagen, Inc.) according to manufacturer's protocols. RNA samples were subjected to DNase digestion using the Turbo DNA-free ${ }^{\text {TM }}$ kit (Ambion; Thermo Fischer Scientific, Inc.). cDNA was synthesized by using ReverTra Ace ${ }^{\circledR}$ qPCR RT kit (Toyobo Life Science) with a random primer $\left(30^{\circ} \mathrm{C}\right.$ for $10 \mathrm{~min}, 42^{\circ} \mathrm{C}$ for $20 \mathrm{~min}$ and $99^{\circ} \mathrm{C}$ for $5 \mathrm{~min}$ ). qPCR was performed using SYBR Premix Ex Taq (Takara Bio, Inc.) in a CFX96 real-time PCR system (Bio-Rad Laboratories, Inc.) following the manufacturer's protocol; thermocycling conditions were as follows: $95^{\circ} \mathrm{C}$ for $30 \mathrm{sec}$, followed by 40 cycles of $95^{\circ} \mathrm{C}$ for $5 \mathrm{sec}$ and $60^{\circ} \mathrm{C}$ for $30 \mathrm{sec}$. Levels of $\mathrm{Nrf} 2$ and p62 were normalized to GAPDH using the $2^{-\Delta \Delta \mathrm{Cq}}$ method (22). The primers used for RT-qPCR were shown in Table SI.

Immunoblotting and immunocytochemistry analyses. Proteins were extracted from cells by $1 \%$ NP-40 in Tris buffer $(50 \mathrm{mM}$ Tris, $150 \mathrm{mM} \mathrm{NaCl}$, pH 8.0, with protease and phosphatase inhibitors; Thermo Fischer Scientific, Inc.). The protein concentration was determined by BCA. Proteins $(20 \mu \mathrm{g})$ were separated on $10 \%$ SDS-PAGE gels and transferred to PVDF membranes. Membranes were blocked with 5\% non-fat milk in PBST (PBS $\mathrm{pH} 7.4$ with $0.2 \%$ Tween-20) for $\mathrm{h}$ at room temperature, followed by incubation at $4{ }^{\circ} \mathrm{C}$ overnight with primary antibodies and washes with PBST (3x10 min at room temperature). Membranes were then incubated with $0.1 \mu \mathrm{g} / \mathrm{ml}$ Dylight 800 anti-rabbit (cat. no. 5230-0412; KPL, Inc.) or Dylight 680 anti-mouse (cat. no. 5230-0406; KPL, Inc.) secondary antibodies in the dark for $2 \mathrm{~h}$ at room temperature. After washing with PBST (3x10 min), images were acquired using a Li-Cor Odyssey Clx Infrared Imaging System (LI-COR Biosciences).

The following primary antibodies were used: Anti-Nrf2 (cat. no. ab137550; 1:2,000; Abcam), anti-p62 (cat. no. 18420-1-AP; 1:3,000; ProteinTech Group,Inc.), anti-FlagTag (cat. no. ANT-146; 1:5,000; Prospec-Tany TechnoGene, Ltd.), anti-phospho-p38 MAPK (Thr180/Tyr182; cat. no. 9211; 1:1,000; Cell Signaling Technology, Inc.), anti-p38 MAPK (D13E1) XP (cat. no. 8690; 1:1,000; Cell Signaling Technology, Inc.), anti- $\beta$-actin (cat. no. 60008-1-Ig; 1:5,000; ProteinTech Group, Inc.) and anti-GAPDH (cat. no. 10494-1-AP; 1:5,000; ProteinTech Group, Inc.).

For the immunocytochemistry, sterilized coverslips were placed in 24-well plates. Cells $(30,000)$ were seeded and cultured for $24 \mathrm{~h}$ before treatment. After treatment, cover slips were washed with PBS (3x10 min at room temperature) and fixed with $4 \%$ paraformaldehyde for $15 \mathrm{~min}$ at room temperature. Cells were then permeabilized with $0.2 \%$ Triton X-100 for $15 \mathrm{~min}$ and blocked with $5 \%$ goat serum (Thermo Fischer Scientific, Inc.) for $1 \mathrm{~h}$ at room temperature. Samples were incubated with primary anti-ubiquitin Lys 48 (cat. no. 05-1307; 1:100; EMD Millipore) and anti-FlagTag antibodies (cat. no. ANT-146; 1:500; Prospec-Tany TechnoGene, Ltd.) at $4^{\circ} \mathrm{C}$ overnight. After washing with PBS (3x10 min at room temperature), cells were incubated with goat anti-mouse Alexa Flour 488- (cat. no. A32723; 1:300) or goat anti-rabbit Alexa Fluor 568-conjugated secondary antibodies (cat. no. A-11011; 1:300; Thermo Fischer Scientific, Inc.) for $2 \mathrm{~h}$ at room temperature, stained with DAPI $(1 \mu \mathrm{g} / \mathrm{ml})$ for $5 \mathrm{~min}$ at room temperature and mounted for fluorescence microscopy examination. Fluorescent microscopy was performed with a confocal microscope (magnification, $x 63$ ), with $\geq 20$ observations per experiment.

Statistical analysis. Data are presented as the mean \pm SEM. All the experiments were repeated $\geq 3$ times. Statistical analysis was performed using one-way ANOVA followed by Tukey's multiple comparison test using GraphPad Prism 8 (GraphPad Software, Inc.). Detailed information about statistical analysis for each experiment are presented in the figure legends. $\mathrm{P}<0.05$ was considered to indicate a statistically significant difference.

\section{Results}

Inhibition of protein synthesis blocks MG132-induced aggresome formation and Nrf2 accumulation. Previous studies have demonstrated that UbK48-linked polyubiquitin conjugates are proximal substrates of proteasomal proteolysis (23). During proteasomal stress, UbK48-linked polyubiquitinated proteins accumulate and package to form aggresome, which are recognized by antibodies. UbK48-positive structures are co-localized with other aggresome markers, such as p62, HDAC6 and PINK1S $(13,24,25)$. To examine the role of just synthesized proteins in aggresome formation, we studied aggresome formation efficiency in MG132-treated cells after blocking transcription by ActD or translation by ANI. Immunostaining showed that $58.4 \%$ of cells formed UbK48-positive aggresomes in MG132-treated 293 cells and $4.4 \%$ of positive staining was observed in MG132+ANI-treated cells. ActD+MG132 treatment did not completely inhibit aggresome formation; however, there was a significant decrease in the number of aggresome containing cells after treatment with MG132+ActD compared with the MG132-treated cells (Fig. 1A). ActD treatment resulted in an accumulation of poly-ubiquitinated proteins in the nucleus, which may be caused by recruitment of ubiquitin E3 ligase into nuclear, such as murine double minute protein (26). We further examined aggresome formation efficiency by treating cells with MG132 and adding ANI at different incubation times (Fig. 1B). Inhibition of protein translation by ANI added after $2 \mathrm{~h}$ of MG132 pretreatment blocked aggresome formation in 293 cells. Aggresome formation efficiency increased to $37.9 \%$ when translation was blocked after $4 \mathrm{~h}$ of MG132 pretreatment and after $6 \mathrm{~h}$ of MG132 pretreatment, ANI had 

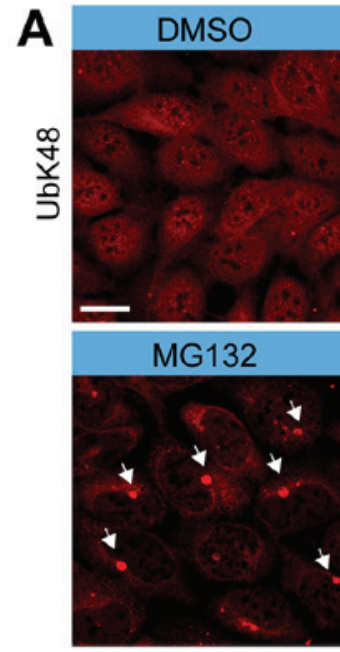

B

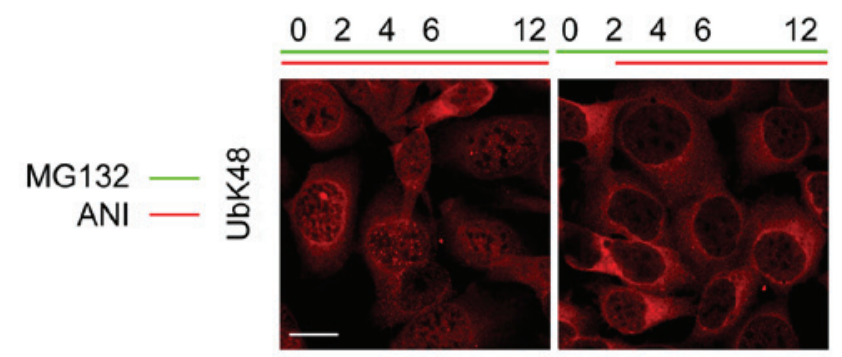

02246

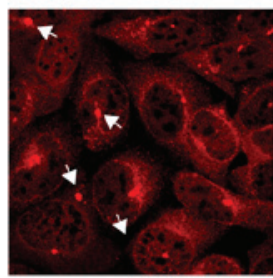

1202546
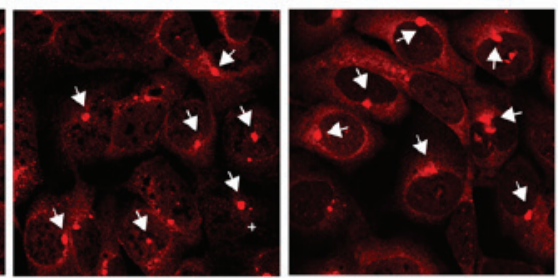

C

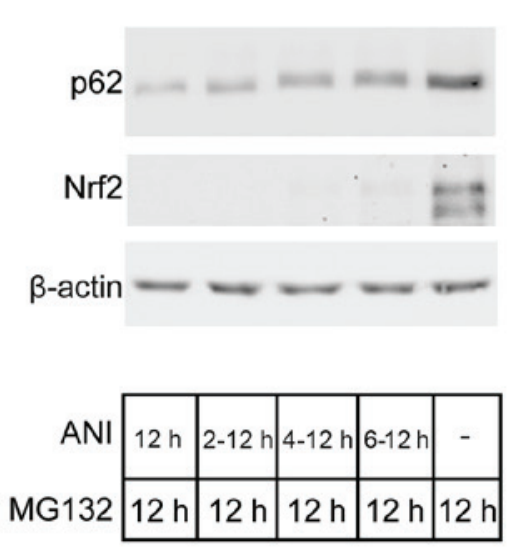

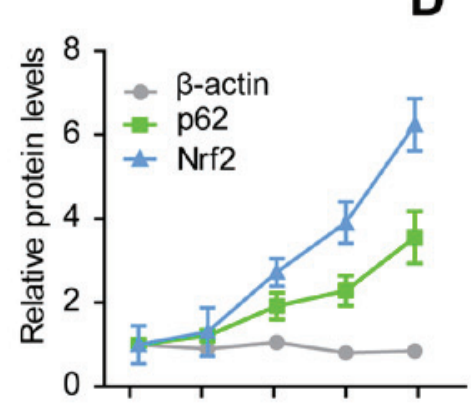

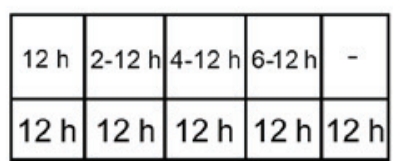

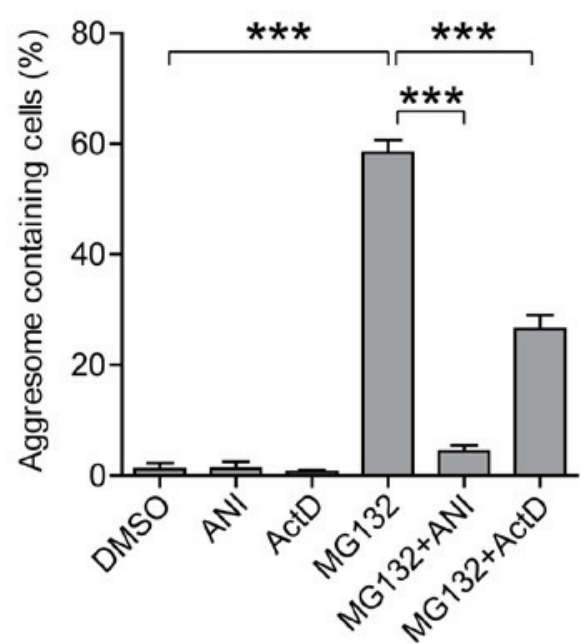
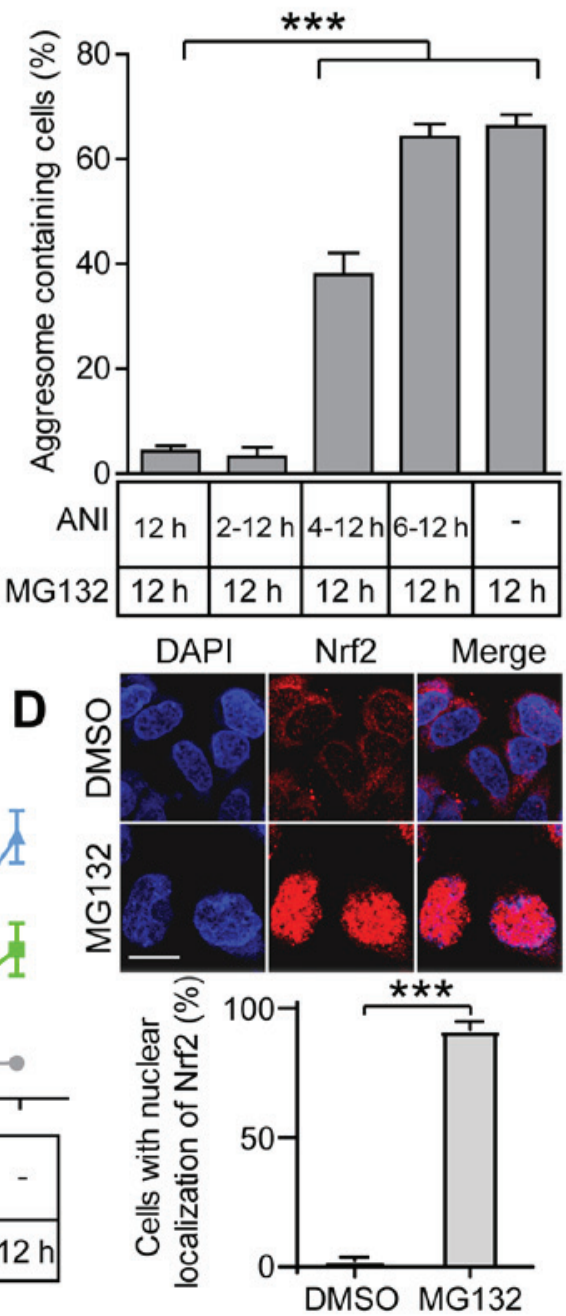

Figure 1. Inhibition of protein synthesis blocks proteasome inhibitor-induced aggresome formation. (A) Representative images and quantification of aggresomes in DMSO, MG132, MG132+ANI and MG132+ActD treated cells. 293 cells were treated with ANI (5 $\mu \mathrm{g} / \mathrm{ml})$, ActD (2 $\mu \mathrm{g} / \mathrm{ml})$ and/or MG132 (2 $\mu \mathrm{M})$ for $12 \mathrm{~h}$ and stained with anti-UbK48 to visualize aggresomes (arrowheads); scale bar, $20 \mu \mathrm{m}$. (B) Representative images and quantification of aggresomes in cells treated with MG132 $(2 \mu \mathrm{M})$ and/or ANI (5 $\mu \mathrm{g} / \mathrm{ml})$ for the indicated periods and aggresomes were stained with anti-UbK48 (arrowheads); scale bar, $20 \mu \mathrm{m}$. (C) Representative immunoblots and quantification of Nrf2 and p62 in cells treated by MG132 ( $2 \mu \mathrm{M})$ and/or ANI (5 $\mu \mathrm{g} / \mathrm{ml})$. (D) Representative images and quantification of Nrf2 in DMSO and MG132 treated cells. The 293 cells were treated with MG132 $(2 \mu \mathrm{M})$ for $12 \mathrm{~h}$ and stained with anti-Nrf2 antibody to visualize the localization of endogenous Nrf2; DAPI was used to detect nuclei; scale bar, $20 \mu \mathrm{m}$. Data are presented as the mean \pm SEM and were assessed using one-way ANOVA followed by Tukey's test. ${ }^{* * *} \mathrm{P}<0.001$. Nrf2, nuclear factor erythroid 2-related factor 2; UbK48, ubiquitin Lys 48; ANI, anisomycin; ActD, actinomycin D.

no effect on aggresome formation efficiency compared with the MG132-terated cells (Fig. 1B). These data indicated that protein translation in the first hours during proteasomal stress was critical for aggresome formation. 

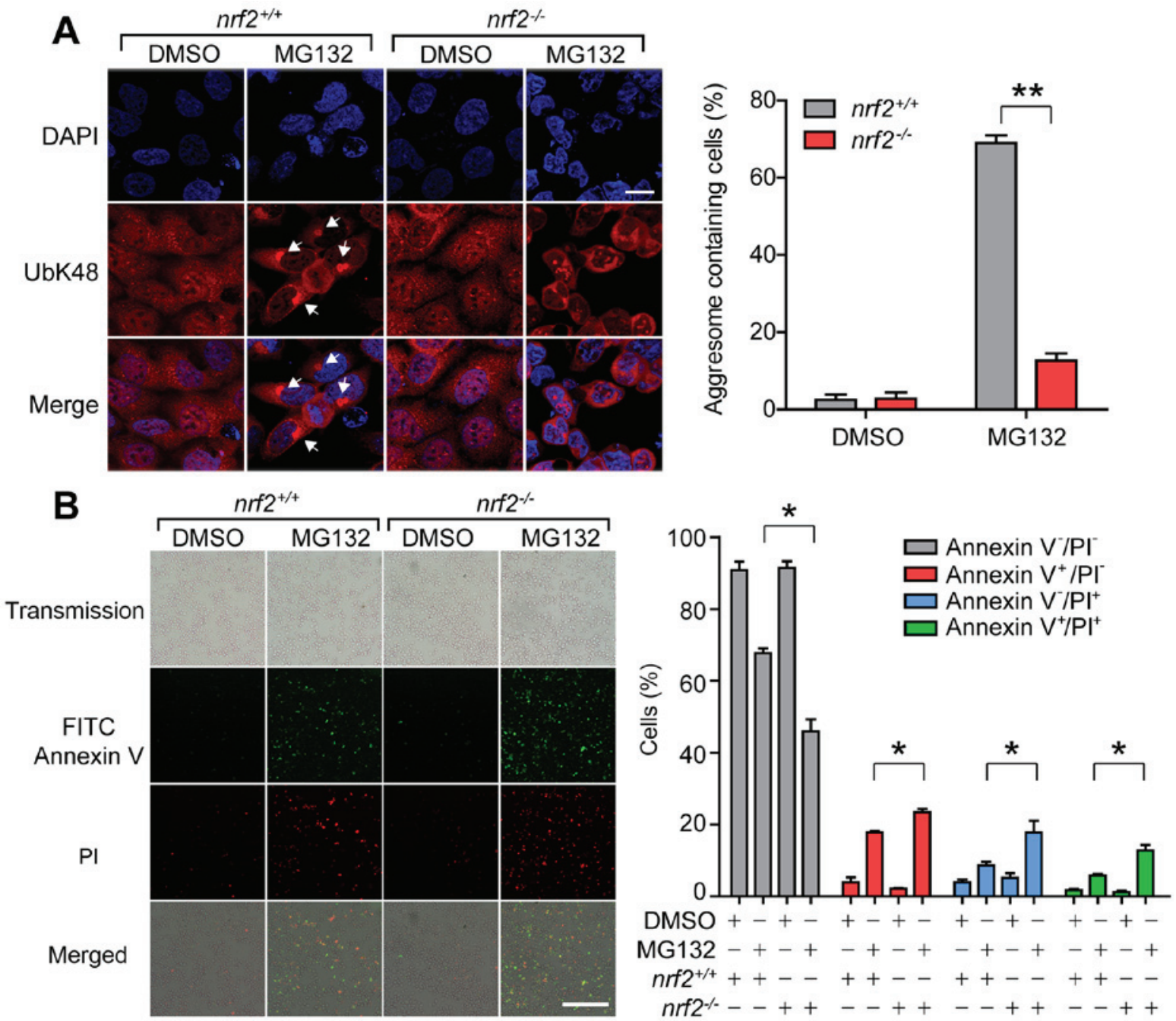

Figure 2. Loss of Nrf2 results in failure of proteasome inhibition-induced aggresome formation. (A) Representative images and quantification of aggresomes in $n r f 2^{+/+}$and $n r f 2^{-/-}$cells after $14 \mathrm{~h}$ treatment with MG132 $(2 \mu \mathrm{M})$. Anti-UbK48 was used to visualize aggresomes (arrowheads) and DAPI staining was used to detect nuclei; scale bar, $20 \mu \mathrm{m}$. (B) Representative images and quantification of $n r f 2^{+/+}$and $n r f 2^{-/}$cells stained with Annexin V (green) and PI (red) after 20 h treatment with DMSO or MG132 $(2 \mu \mathrm{M})$. Live cells, Annexin V'PI; early apoptotic cells, Annexin $\mathrm{V}^{+} \mathrm{PI}$; necrotic cells, Annexin $\mathrm{V}^{-} \mathrm{PI}^{+}$; late apoptotic cells, Annexin $\mathrm{V}^{+} \mathrm{PI}^{+}$; scale bar, $100 \mu \mathrm{m}$. Data are presented as the mean $\pm \mathrm{SEM}$ representative of three independent experiments and were assessed using one-way ANOVA followed by Tukey's test. " $\mathrm{P}<0.05$ and ${ }^{* *} \mathrm{P}<0.01$. Nrf2, nuclear factor erythroid 2-related factor 2; PI, propidium iodide; $n r f 2^{--}$, Nrf2 knockout 293 cells; UbK48, ubiquitin Lys 48.

Immunoblotting analysis revealed that of protein translation induced by ANI prevented Nrf2 accumulation at early stages of stress, compared with the MG132-treated cells (Fig. 1C), and Nrf2 was localized in the nucleus after MG132 treatment (Fig. 1D). Furthermore, 0.1 to $10 \mu \mathrm{M}$ MG132 treatment showed that Nrf2 accumulated in a dose-dependent manner (Fig. S1). Levels of p62, critical for poly-ubiquitinated proteins to form microaggresomes during proteasome inhibition, were higher in MG132-treated cells compared with ANI+MG132-treated groups (Fig. 1C). These results suggested that stress-induced protein synthesis, including the synthesis of Nrf2 and p62, may be essential for aggresome formation.

Loss of Nrf2 results in failure of aggresome formation. If Nrf2 was required for MG132-induced aggresome formation, we hypothesized that knockout of Nrf2 may interfere with aggresome formation and cell survival after MG132 treatment. To test this, we generated Nrf2 knockout cell lines using CRISPR/Cas9 (Fig. S2A) (21). Nrf2 is rapidly processed by UPS $(27,28)$, but protein levels were detected by western blot in 293 cells following MG132 treatment to induce rapid accumulation of Nrf2 (Fig. S2B). As expected, deleting the first exon of $N E L 2 L$ resulted in loss of Nrf2 protein expression in $n r f 2^{-/}$cells (Fig. S2B). Further PCR analysis of the monoclonal cell lines without Nrf2 expression showed that the first exon of $N E L 2 L$ was successfully deleted (Fig. S2C and D). To determine aggresome formation efficiency in $n r f 2^{+/+}$and $n r f 2^{-1-}$ cells, MG132 was used to induce the aggresome formation. A $14 \mathrm{~h}$ treatment with $2 \mu \mathrm{M}$ MG132 induced aggresome formation in $68 \%$ of $n r f 2^{+/+}$and $12.5 \%$ of $n r f 2^{-/-}$cells (Fig. 2A). It has been reported that loss of Nrf2 induces increased reactive oxygen species (ROS) production in cultured cells and mouse brains $(28,29)$, we wanted to evaluate whether aggresome formation defects were caused by increased intracellular ROS in $n r f 2^{-\digamma}$ cells. To reduce intracellular ROS level, we treated $n r f 2^{+/+}$and $n r f 2^{-/}$cells with $\mathrm{N}$-acetyl-cysteine (NAC), an aminothiol and synthetic precursor of intracellular cysteine and GSH (30). NAC treatment had no significant effect on the 
A
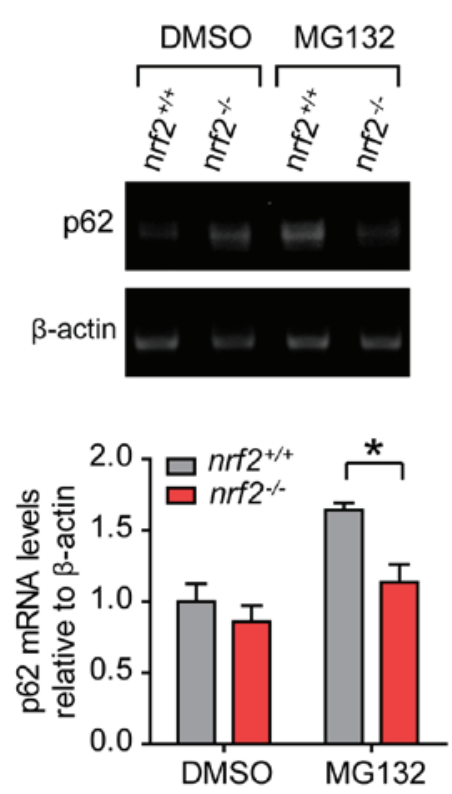

B
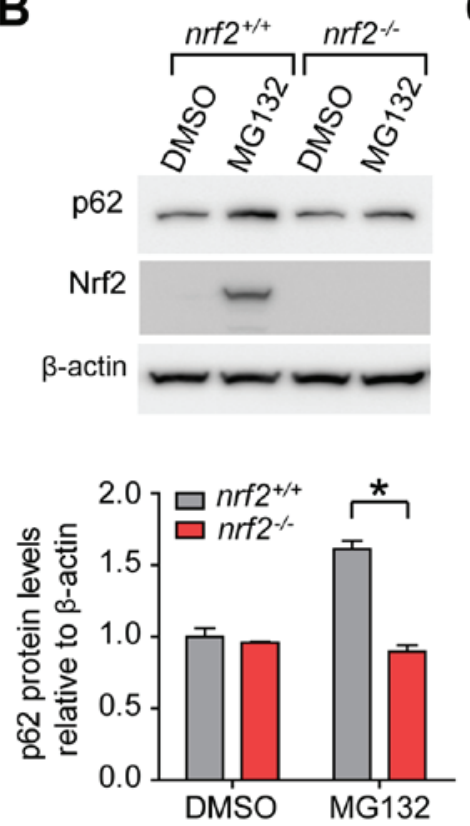

C
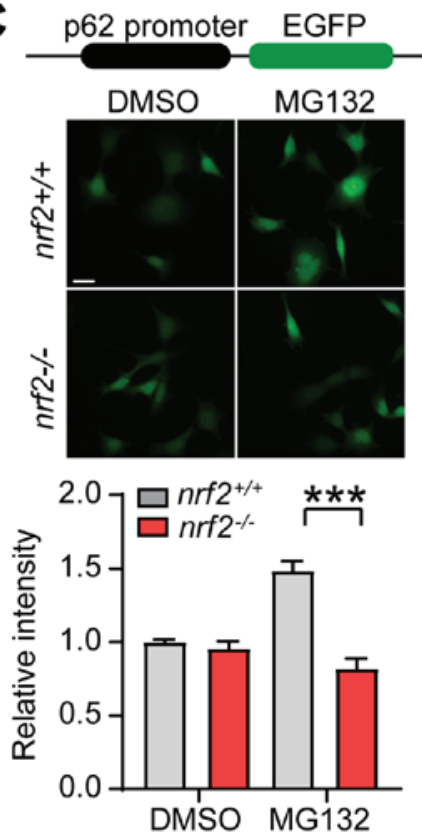

Figure 3. Transcriptional upregulation of p62 during proteasome inhibition is dependent on Nrf2. (A) Representative images and quantification of p62 mRNA in $n r f 2^{+/+}$and $n r f 2^{-/-}$cells treated with DMSO or MG132 for $12 \mathrm{~h}$. (B) Representative immunoblots and quantification of p62 levels in $n r f 2^{+/+}$and $n r f 2^{-/-}$cells treated with DMSO or MG132 (12 h). (C) Representative images and quantification of EGFP expression driven by the p62 promoter in $n r f 2^{+/+}$and $n r f 2^{-/}$cells treated with DMSO or MG132 (12 h). Data are presented as the mean \pm SEM representative of three independent experiments and were assessed using one-way ANOVA followed by Tukey's test. ${ }^{*} \mathrm{P}<0.05$ and ${ }^{* * * *} \mathrm{P}<0.001$. Nrf2, nuclear factor erythroid 2-related factor 2; nrf $2^{-/-}$, Nrf2 knockout 293 cells; EGFP, enhanced GFP.

aggresome formation in $n r f 2^{+/+}$and $n r f 2^{-/-}$cells, suggesting that ROS levels may not influence aggresome formation during proteasome inhibition (Fig. S2E and F).

To explore the time-dependent manner of MG132 induced cell death, we treated 293 cells with $2 \mu \mathrm{M}$ MG132 and analyzed cytotoxicity with FITC-Annexin V and PI assays. After 20 h treatment with MG132, changes in viability were significant in 293 cells (Fig. S3). We further treated $n r f 2^{+/+}$and $n r f 2^{-/}$cells with $2 \mu \mathrm{M}$ MG132 for $20 \mathrm{~h}$ to induce apoptosis and necrosis. The cell viability assay demonstrated that the loss of Nrf2 significantly increased the cells susceptibility towards proteasomal inhibition-triggered cell death following MG132 treatment (Fig. 2B). MG132 treatment induced apoptosis in $8.7 \%$ and necrosis in $5.8 \%$ of $n r f 2^{+/+}$cells, and in $n r f 2^{-/-}$ cells, apoptosis and necrosis rates increased to 17.7 and $12.7 \%$, respectively.

Transcriptional upregulation of p62 during proteasome inhibition is dependent on Nrf2. The presence of the ARE in the p62 gene suggests that p62 may be transcriptionally activated by Nrf2 during proteasome inhibition (17). To test this hypothesis, we examined mRNA and protein levels of p62 in $n r f 2^{+/+}$ and $n r f 2^{-/-}$cells. mRNA and protein levels of p62 were significantly increased in $n r f 2^{+/+}$cells when treated with MG132 and this response was inhibited by Nrf2 knockout (Fig. 3A and B). Similar to p62, heme oxygenase-1, a gene regulated by Nrf2 during proteasome inhibition (31), expression decreased in $n r f 2^{-/-}$cells compared with $n r f 2^{+/+}$cells following MG132 treatment (Fig. S4A and B). This further indicated that Nrf2 may be essential for the transcriptional activation of stress-response genes. To exclude the possibility that Nrf2 may affect the activity of other transcriptional factors, we evaluate protein levels of HSP70, samples in which the transcriptional activation was driven by HSF1 during MG132 treatment (32). Loss of Nrf2 had no effect on HSP70 expression compared with $n r f 2^{+/+}$cells (Fig. S4C and D).

To further examine the transcriptional regulation of p62 by Nrf2, we cloned $\sim 1.8 \mathrm{~kb}$ of the human p62 promoter region upstream of EGFP (33). The reporter gene was expressed in $n r f 2^{+/+}$and $n r f 2^{-/-}$cells, and MG132 treatment significantly increased EGFP expression in $n r f 2^{+/+}$but not $n r f 2^{-/-}$cells (Fig. 3C). The loss of Nrf2 inhibited aggresome formation and p62 transcriptional activation during proteasome inhibition.

Expression of p62 rescues proteasomal stress response defects in Nrf 2 knockout cells. Proteasome inhibition stimulates p62 ubiquitin binding activity by phosphorylation and assembles ubiquitinated cargos into microaggregates through self-oligomerization $(13,34,35)$. Loss of p62 suppresses the formation of aggresomes and clearance of poly-ubiquitinated proteins during MG132 treatment in 293 cells (12). If the Nrf2 knockout induced proteasome formation, defects may be dependent on the loss of p62 in 293 cells, overexpression of p62 in $n r f 2^{-/-}$cells may rescue these defects. To this end, we generated $n r f 2^{-/}\left[\right.$Flag-Nrf2] and $n r f 2^{-/-}[$Flag-p62] stable cell lines by lentivirus-transduction (Fig. S5).

A $14 \mathrm{~h}$ treatment with $2 \mu \mathrm{M}$ MG132 induced aggresome formation in $68.8 \%$ of $n r f 2^{+/+}$cells, but aggresome-containing cells in the $n r f 2^{-/-}$[Vector] cell line was decreased to $17.1 \%$ (Fig. 4A). In $n r f 2^{-/-}$cells, overexpression of Flag-Nrf2 rescued aggresome formation in $72.5 \%$ of cells and overexpression of Flag-p62 rescued aggresome formation efficiency to $51 \%$, suggesting that p62 protein levels may be critical for aggresome formation. The aggresome formation efficiency in $n r f 2^{-/-}$[Flag-p62] cells lower than that of the $n r f 2^{-/-}$[Flag-Nrf2] 
A

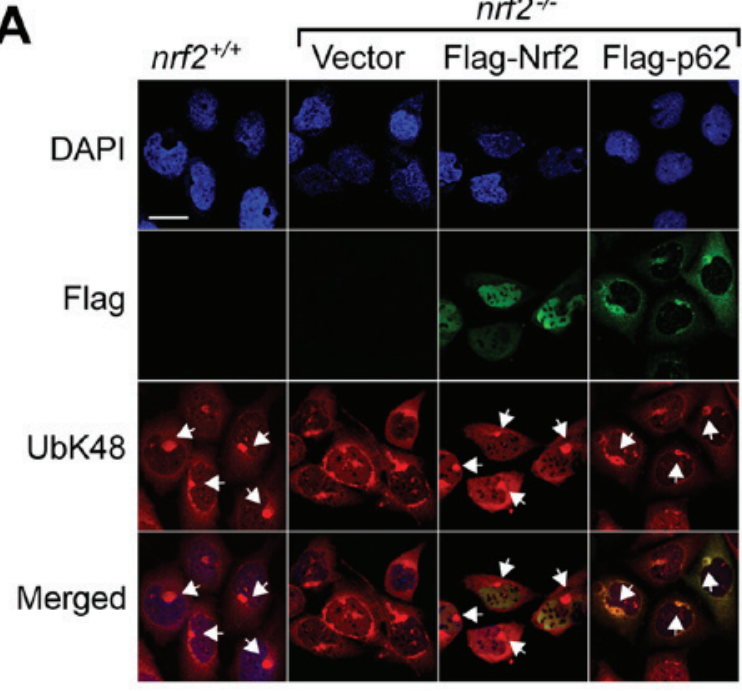

B

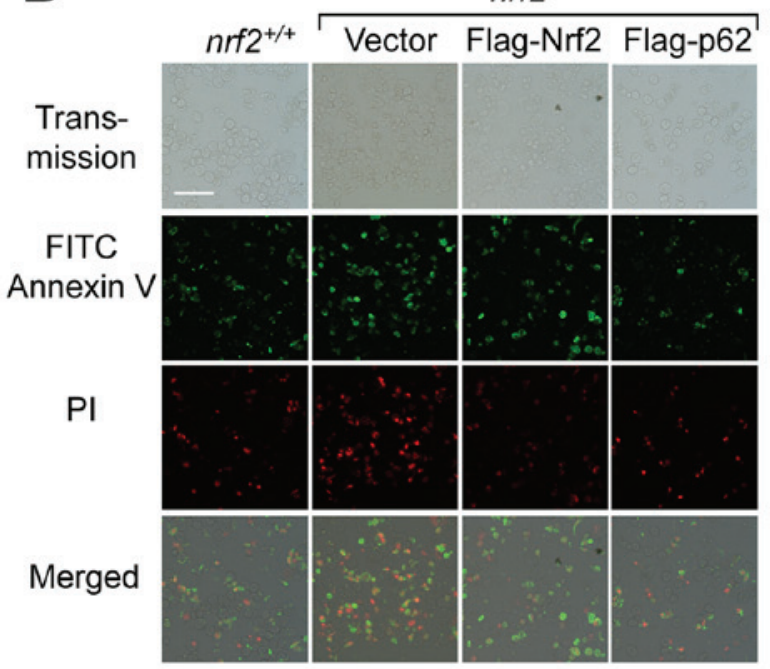

C

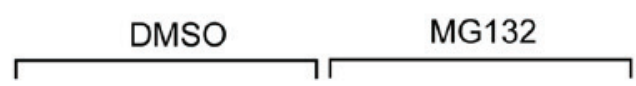

p62

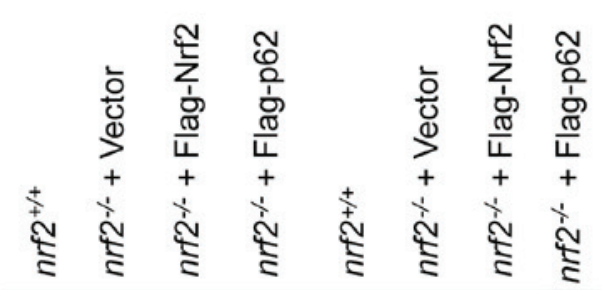

Nrf2

$\beta$-actin
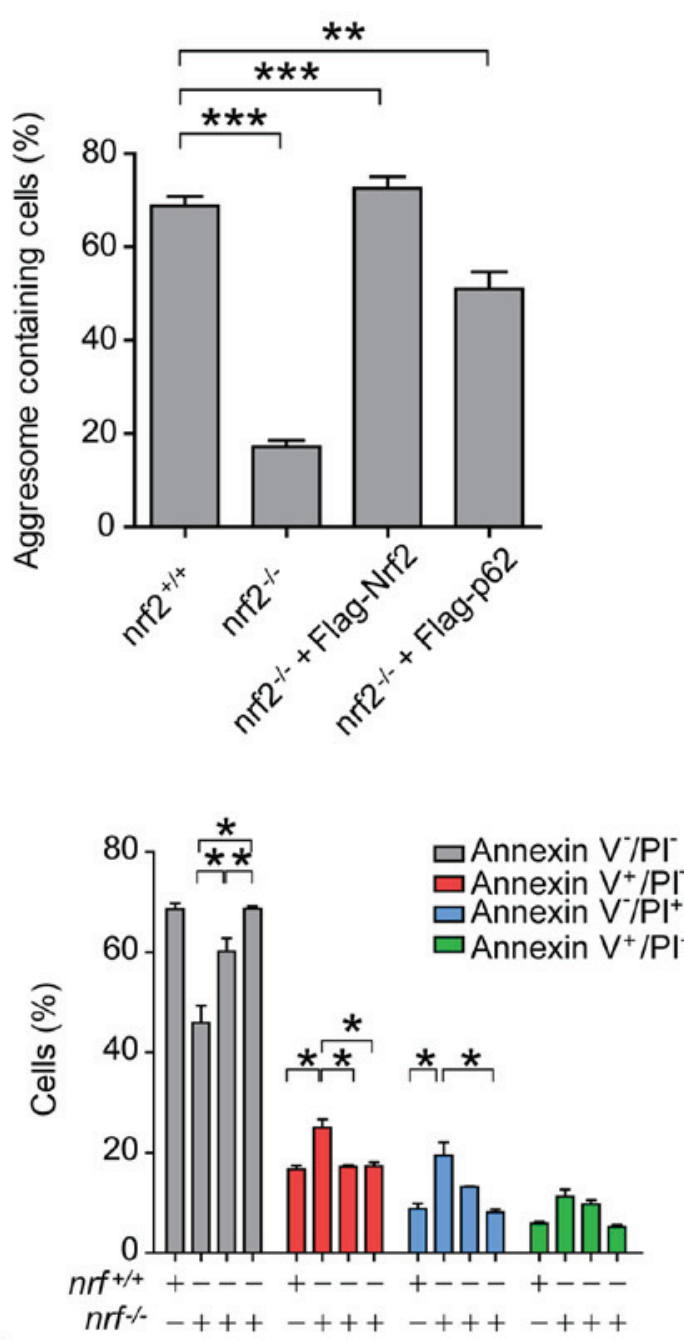

nrf ${ }^{-/}-$Flag-Nrf2 --+---+---+---+$n r^{-/}-/$Flag-p62 --- + - - + ---+---+

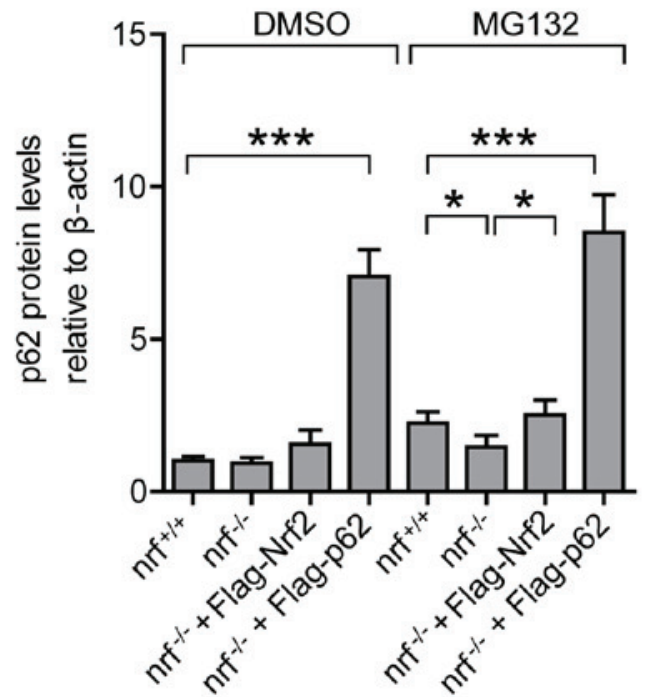

Figure 4. Expression of p62 rescues the defects of proteasomal stress response in Nrf2 knockout cells. (A) Representative images and quantification of aggresomes in $n r f 2^{+/+}, n r f 2^{-/}$[Vector], $n r f 2^{-/-}\left[\right.$Flag-Nrf2] and $n r f 2^{-/-}$[Flag-p62] cells after 14 h treatment with MG132 (2 $\mu$ M). Anti-UbK48 was used to visualize ubiquitin-containing aggresomes (arrowheads), anti-Flag was used to visualize exogenous Nrf2 and p62, and DAPI was used to detect nuclei; scale bar, $20 \mu \mathrm{m}$. (B) Representative images and quantification of $n r f 2^{+/+}, n r f 2^{-/-}$[Vector], $n r f 2^{-/-}$[Flag-Nrf2] and $n r f 2^{-/ /}$[Flag-p62] cells stained with Annexin V (green) and PI (red) after $20 \mathrm{~h}$ treatment with DMSO or MG132. Live cells, Annexin V-PI; early apoptotic cells, Annexin $\mathrm{V}^{+} \mathrm{PI}^{-}$; necrotic cells, Annexin $\mathrm{V}^{-} \mathrm{PI}^{+}$; late apoptotic cells, Annexin $\mathrm{V}^{+} \mathrm{PI}^{+}$; scale bar, $100 \mu \mathrm{m}$. (C) Representative immunoblots and quantification of p62 and Nrf2 levels in $n r f 2^{+/+}, n r f 2^{-/}[\mathrm{Vector}], n r f 2^{-/-}[\mathrm{Flag}-\mathrm{Nrf} 2]$ and $n r f 2^{-/}[$Flag-p62]. Data are presented as the mean \pm SEM representative of three independent experiments and were assessed using one-way ANOVA followed by Tukey's test. ${ }^{*} \mathrm{P}<0.05,{ }^{* *} \mathrm{P}<0.01$ and ${ }^{* * * *} \mathrm{P}<0.001$. Nrf2, nuclear factor erythroid 2-related factor 2; PI, propidium iodide; $n r f 2^{-/}$, Nrf2 knockout 293 cells; UbK48, ubiquitin Lys 48; [], transfection construct. 

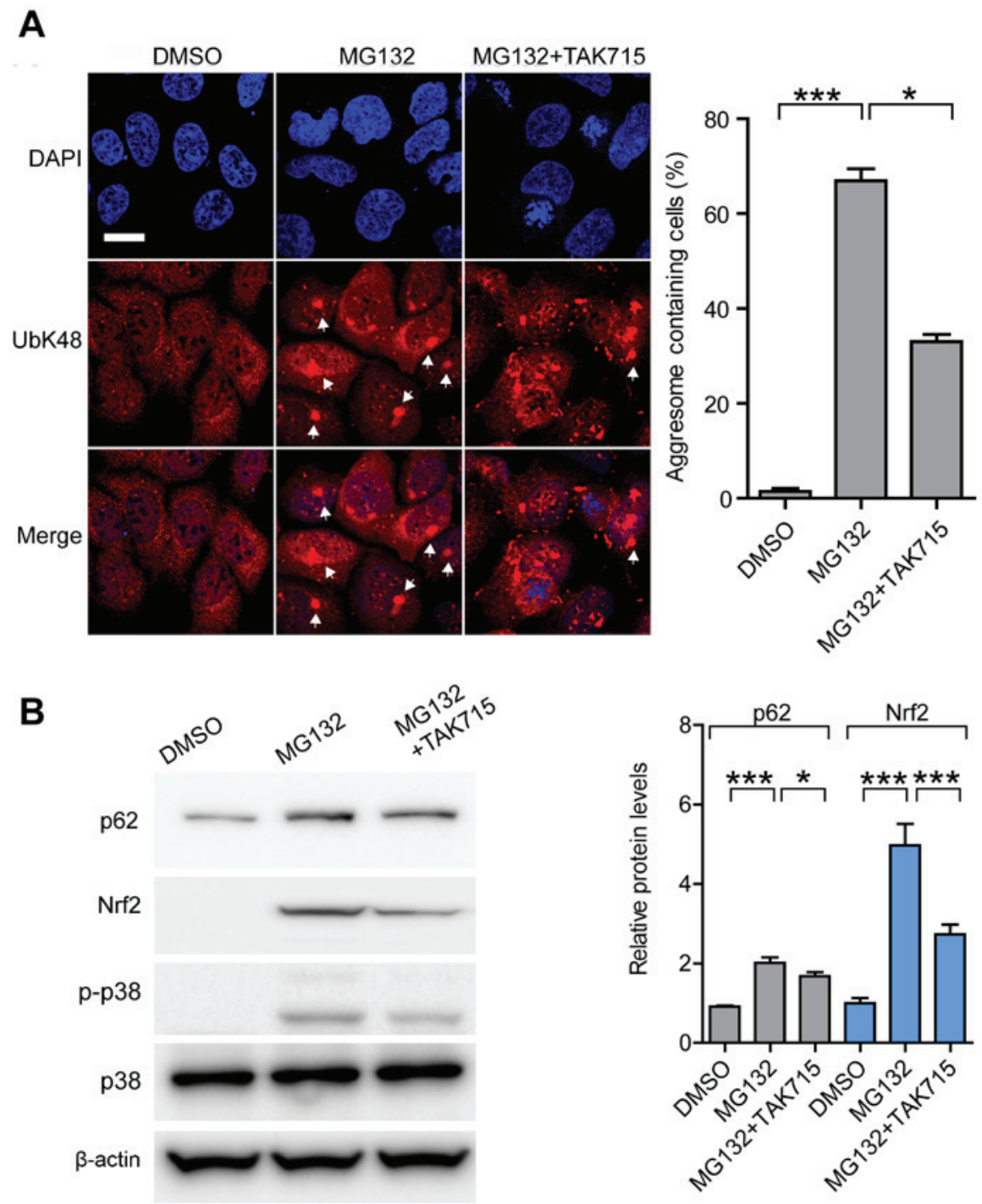

Figure 5. MAPK/p38 inhibitor attenuates aggresome formation through Nrf2-mediated transcriptional activation. (A) Representative images and quantification of aggresomes in DMSO, MG132 or MG132+TAK715 treated cells (12 h). Anti-UbK48 was used to visualize aggresomes (arrowheads) and DAPI was used to detect nuclei; scale bar, $20 \mu \mathrm{m}$. (B) Representative immunoblots and quantification of Nrf2 and p62 in treated cells. Data are presented as the mean \pm SEM representative of three independent experiments and were assessed using one-way ANOVA followed by Tukey's test. " $\mathrm{P}<0.05$ and ${ }^{* * * *} \mathrm{P}<0.001$. Nrf2, nuclear factor erythroid 2-related factor 2; UbK48, ubiquitin Lys 48; p-, phosphorylated.

cells, indicating that other targets regulated by Nrf2 are involved in aggresome formation. A $20 \mathrm{~h}$ treatment with $2 \mu \mathrm{M}$ MG132 induced apoptosis in $19.5 \%$ and necrosis in $11.2 \%$ of the $n r f 2^{-1}$ [Vector] cells, and in $n r f 2^{-1-}$ [Flag-Nrf2] cells, apoptosis and necrosis rates were reduced to 13.2 and $9.7 \%$, respectively (Fig. 4B). Overexpression of Flag-p62 in $n r f 2^{-1}$ cells decreased apoptosis and necrosis rates to 8.1 and 5.1\%, respectively, suggesting that Nrf2-mediated transcriptional activation of p62 was required to minimize proteasomal stress-induced necrosis and apoptosis. Immunoblotting analysis showed that overexpression of Flag-Nrf2 rescued MG132-induced transcriptional activation of p62 deficits in $n r f 2^{-1-}$ [Vector] cells (Fig. 4C). Exogenous expressed Flag-Nrf2 in $n r f 2^{-/}$cells significantly increased after MG132 treatment compared with the unstressed condition, further supporting that Nrf2 was sensitive to proteasome inhibition (Fig. 4C). Together, these results confirmed that Nrf2-mediated transcriptional activation of p62 was essential for aggresome formation during proteasome dysfunction.
Nrf2 mediated aggresome formation depends on $\mathrm{p} 38 / \mathrm{MAPK}$ kinase activity. It has been reported that $\mathrm{Nrf} 2$ activation is p38/MAPK-dependent, which compromises the cytotoxic effects through activating transcription of downstream targeting genes during proteasome inhibition (36). We blocked p38/MAPK activity using the specific inhibitor TAK715 to examine, if Nrf2-mediated aggresome formation in MG132-treated cells was dependent on the p38/MAPK pathway. Consistent with the previous study, p38 inhibitor TAK715 partially inhibited activation of p38-induced by proteasomal inhibition; the efficiency of aggresome formation in MG132+TAK715-treated cells decreased by $50 \%$ compared with the MG132-treated cells (Fig. 5A). Western blot analysis confirmed that protein levels of Nrf2 and p62 significantly decreased in MG132+TAK715-treated cells compared with the MG132-treated cells (Fig. 5B). Taken together, blocking Nrf2 activation through suppression of the p38/MAPK signaling pathway may decrease the efficiency of aggresome formation. 


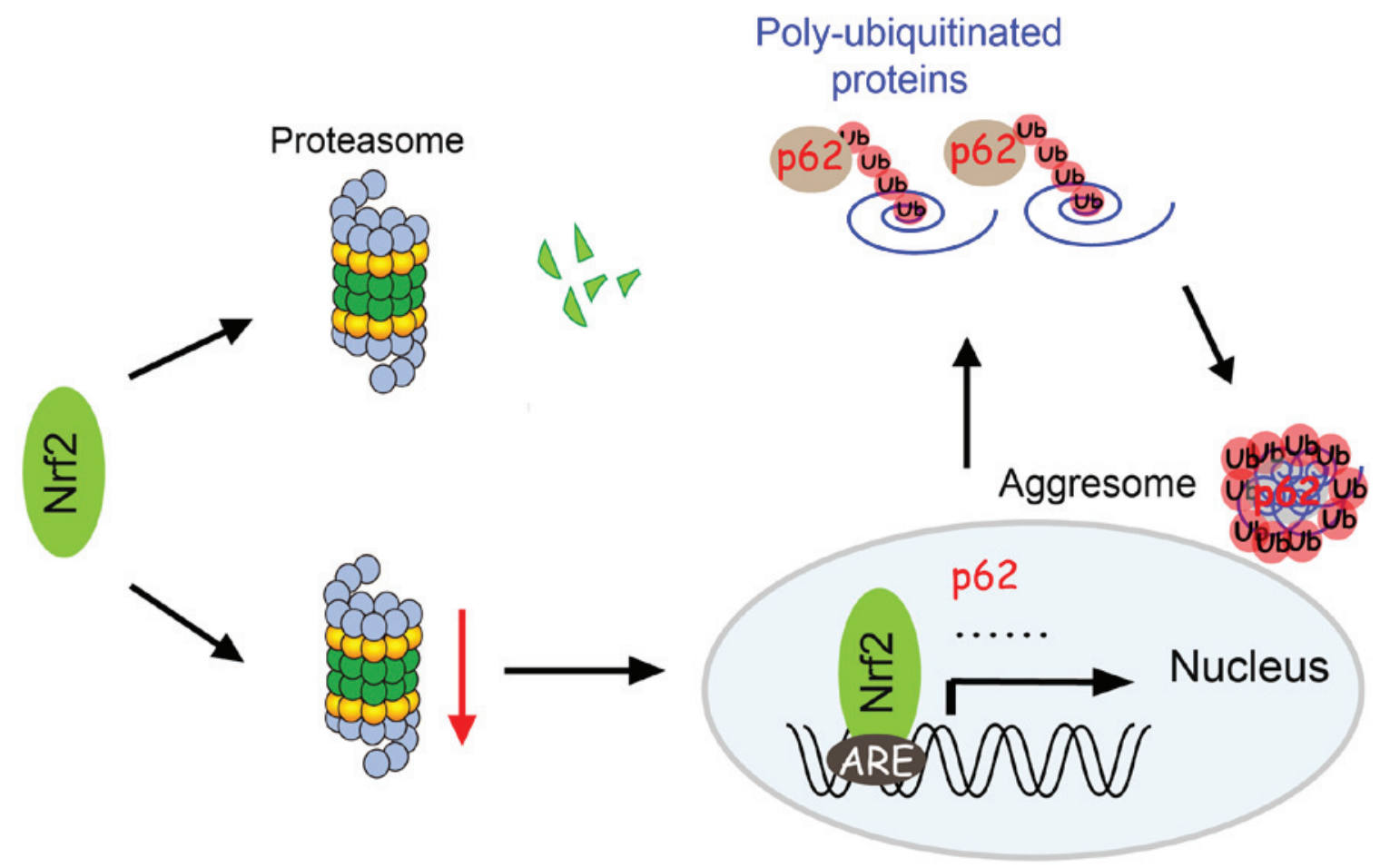

Figure 6. Schematic model for the induction of aggresome formation by NRF2 during proteasome inhibition. Under physiological conditions, Nrf2 is degraded by the Ub proteasome system. In cells with reduced proteasome activity, Nrf2 is stabilized and accumulates in the nuclei. Through transcriptional activation of p62, Nrf2 promotes aggresomes formation. Through functioning as a sensor of cytosolic proteasome activity and an activator of aggresome formation, Nrf2 alleviates cell damages caused by proteasomal stress. Nrf2, nuclear factor erythroid 2-related factor 2; ARE, antioxidant response elements; Ub, ubiquitin.

\section{Discussion}

The aggresome has emerged as a key stress-response subcellular structure in the clearance of misfolded protein aggregates during many stress conditions, which are often linked with cell death in neurodegenerative diseases (37). Despite the potential importance of the aggresome in managing the stress response and its association with disease, few proteins critical for aggresome formation have been identified (38-40). In this study, we reported that Nrf2 was crucial for aggresome formation and cell survival in response to proteasome inhibition-induced stress. Based on our results, we proposed a model, which described that Nrf2-mediated mRNA transcription may be induced through cellular stress and mediated by proteasome dysfunction (Fig. 6).

During mRNA translation, the synthesized polypeptide chain is elongated by the ribosome with the linear chain folding into its three dimensional structure and then being targeted to a precise intracellular location. If misfolded, the polypeptides are rapidly degraded by UPS $(41,42)$. However, when UPS is impaired or overwhelmed, misfolded polypeptides are sequestered into microaggregates and then retrogradely transported to the microtubule-organizing center to form aggresomes $(43,44)$. How does the UPS dysfunction activate downstream signals to form the aggresome? As shown in previous studies, during proteasome inhibition, newly synthesized proteins play a special regulatory role in the initiation of aggresome formation $(40,45)$. Therefore, we hypothesized that inhibitors of transcription and translation may suppress aggresome formation. Inhibition of protein translation by ANI completely inhibited aggresome formation, whereas transcriptional inhibitor ActD, which prevents mRNA synthesis, only partially reduced the efficiency of aggresome formation. These data supported the notion that translational regulation provided immediate and effective changes in protein levels involved in aggresome formation. However, transcriptional regulation is essential in mediating the strength of stress response (46).

Cells activate mechanisms to regulate gene expression after exposure to environmental stress, largely at the transcriptional level. These stress responses enable cells to cope with and adapt to stressful situations, such as starvation, oxidative and DNA damage (47). A central mechanism for the regulation of stress-induced transcription is mediated by activation of the specific transcriptional factors (48). Transcriptional factor Nrf2 is the major regulator of cytoprotective responses to oxidative and electrophilic stress (49). Nrf2 is rapidly turned over by UPS, with a short half-life under physiological conditions (7-15 $\mathrm{min}$ ) that is increased to $30-100 \mathrm{~min}$ in the presence of a stress inducer $(50,51)$. Proteasome inhibitors, such as clasto-lactacystin, $\beta$-lactone, MG132 and MG115, lead to the rapid accumulation of Nrf2 in the nuclei $(52,53)$. Here, we showed that MG132, at low concentration, such as $0.5 \mu \mathrm{M}$ and $1 \mu \mathrm{M}$, induced $\mathrm{Nrf} 2$ accumulation, indicating that $\mathrm{Nrf} 2$ was extremely sensitive to proteasome inhibition making it a potential candidate to serve as an upstream modulator in the proteasomal stress response. Nrf2 knockout cells displayed reduced efficiency in aggresome formation, as well as increased cell death. This phenotype was suppressed by the overexpression of Nrf2 and p62, suggesting that the reduced aggresome formation efficiency in $n r f 2^{-/-}$cells may be due to their lack of p62. These results supported claims of a major role of $\mathrm{Nrf} 2$ in 
the transduction of proteasome impairment signaling to the downstream aggresome-autophagy machinery.

Loss the Nrf2 expression caused decreases in aggresome formation efficiency (68.7 and $17.1 \%$ for $n r f 2^{+/+}$and $n r f 2^{-/-}$, respectively), while transcriptional inhibitor ActD only reduced the efficiency to $37.9 \%$. The data suggested that Nrf2 regulated aggresome formation not only through transcriptional upregulation of targeting mRNA, such as p62, but also through an unknown pathway. Loss of Nrf2 leads to mitochondrial depolarization, decreased ATP levels and impaired respiration (54). Microaggregate transport, through the microtubule mediated by HDAC6, is an energy-consuming process (3), and decreased ATP levels may contribute to aggresome formation defects in $n r f 2^{-/}$cells, a process which is independent of Nrf2-regulated transcriptional reprogramming. Although overexpression of p62 restored aggresome formation efficiency to $51 \%$, levels were still different compared with $n r f 2^{-/-}[$Flag-Nrf2] cells $(72.5 \%)$, indicating that Nrf2 influenced aggresome formation through multiple pathways. Genetic activation of Nrf2 by deletion of Keapl increases the mitochondrial membrane potential and ATP levels, the rate of respiration and the efficiency of oxidative phosphorylation (54). This may explain the small increase of aggresome formation efficiency in Nrf2 overexpressing in $n r f 2^{-/-}$cells compared with the $n r f 2^{+/+}$[Vector] cells. Further studies are needed to evaluate the association between Nrf2-mediated mitochondrial function and aggresome formation.

Proteasome inhibitors have been shown to induce aggresome formation in many cell types, including 293, MEF, as well as neuronal-like cells PC12 and N2A, in a time- and dose-dependent manner (26,55-57). However, some misfolded proteins form dispersed aggregates rather than aggresomes during proteasome inhibition, such as HeLa, Huh7 and Cos7 $(55,58)$. In contrast to aggresomes formed around MTOC, dispersed aggregates are distributed in the cells and do not result in cytoskeleton rearrangements, suggesting that dispersed aggregates may represent intermediate particles during aggresome assembly $(24,58)$. The defects of aggresome formation in these cells may be caused by the lack of critical regulators of aggresome assembly, such as the subtype of p38 kinase (24). Due to their biochemical and morphological similarities to the protein inclusion bodies in neurodegenerative diseases, aggresomes have received much attention in the past twenty years $(41,59)$. Aggresomes have been thought to play a critical role in protein surveillance and the pathogenesis of neurodegenerative diseases (60). Induction of aggresome formation can increase cell survival when overexpressing a mutant huntingtin fragment in primary cultured neuronal cells (61). Reducing the load of aggresomes by genetically inhibiting ubiquitination enhances polyQ-mediated neuronal death in a mouse model (62). An Nrf2-mediated aggresome formation mechanism may not only explain the activation of autophagy by proteasome dysfunction, but also implicate the inefficient switch between different protein degradation pathways, as one pathological mechanism of neurodegenerative diseases.

In summary, our study revealed transcriptional events associated with $\mathrm{Nrf} 2$ as critical signaling modules for the perinuclear aggresome formation during proteasomal stress (Fig. 6). These findings supported claims that the stress-induced aggresome-autophagy pathway may be critical for cell survival during proteasomal failure. Given that protein aggregation and accumulation is related to many diseases (63), our findings suggested the p38/Nrf2/p62 pathway as an important therapeutic target.

\section{Acknowledgements}

Not applicable.

\section{Funding}

This work was supported by the National Natural Science Foundation of China (grant nos. 30871032 and 31600616), the Natural Science Foundation of Fujian Province (grant no. 2017J05142), the Scientific Foundation of Fuzhou Health Department (grant no. 2016-S-124-10) and the Scientific Foundation of Fujian Provincial Health Commission (grant no. 2016-1-87).

\section{Availability of data and materials}

The datasets used and/or analyzed during the current study are available from the corresponding author on reasonable request.

\section{Authors' contributions}

CJ and JG conceived and designed the experiments. SQ and JG performed experiments and analyzed the data. JG wrote the paper. All authors read and approved the final manuscript.

\section{Ethics approval and consent to participate}

Not applicable.

\section{Patient consent for publication}

Not applicable.

\section{Competing interests}

The authors declare that they have no competing interests.

\section{References}

1. Corboy MJ, Thomas PJ and Wigley WC: Aggresome formation. Methods Mol Biol 301: 305-327, 2005

2. Johnston JA, Ward CL and Kopito RR: Aggresomes: A cellular response to misfolded proteins. J Cell Biol 143: 1883-1898, 1998.

3. Kawaguchi Y, Kovacs JJ, McLaurin A, Vance JM, Ito A and Yao TP: The deacetylase HDAC6 regulates aggresome formation and cell viability in response to misfolded protein stress. Cell 115: 727-738, 2003

4. Webb JL, Ravikumar B and Rubinsztein DC: Microtubule disruption inhibits autophagosome-lysosome fusion: Implications for studying the roles of aggresomes in polyglutamine diseases. Int J Biochem Cell Biol 36: 2541-2550, 2004.

5. Tanaka M, Kim YM, Lee G, Junn E, Iwatsubo T and Mouradian MM: Aggresomes formed by alpha-synuclein and synphilin-1 are cytoprotective. J Biol Chem 279: 4625-4631, 2004.

6. Rubinsztein DC, Ravikumar B, Acevedo-Arozena A, Imarisio S, O'Kane CJ and Brown SD: Dyneins, autophagy, aggregation and neurodegeneration. Autophagy 1: 177-178, 2005. 
7. Marambio P, Toro B, Sanhueza C, Troncoso R, Parra V, Verdejo H, García L, Quiroga C, Munafo D, Díaz-Elizondo J, et al: Glucose deprivation causes oxidative stress and stimulates aggresome formation and autophagy in cultured cardiac myocytes. Biochim Biophys Acta 1802: 509-518, 2010.

8. Kovacs I, Lentini KM, Ingano LM and Kovacs DM: Presenilin 1 forms aggresomal deposits in response to heat shock. Journal of molecular neuroscience : J Mol Neurosci 29: 9-19, 2006.

9. Ang E, Pavlos NJ, Rea SL, Qi M, Chai T, Walsh JP, Ratajczak T, Zheng MH and Xu J: Proteasome inhibitors impair RANKL-induced NF-kappaB activity in osteoclast-like cells via disruption of p62, TRAF6, CYLD, and IkappaBalpha signaling cascades. J Cell Physiol 220: 450-459, 2009.

10. Kirkin V, McEwan DG, Novak I and Dikic I: A role for ubiquitin in selective autophagy. Mol Cell 34: 259-269, 2009.

11. Pankiv S, Clausen TH, Lamark T, Brech A, Bruun JA, Outzen H, Øvervatn A, Bjørkøy G and Johansen T: p62/SQSTM1 binds directly to Atg8/LC3 to facilitate degradation of ubiquitinated protein aggregates by autophagy. J Biol Chem 282: 24131-24145, 2007.

12. Gao J, Li M, Qin S, Zhang T, Jiang S, Hu Y, Deng Y, Zhang C, You D, Li H, et al: Cytosolic PINK1 promotes the targeting of ubiquitinated proteins to the aggresome-autophagy pathway during proteasomal stress. Autophagy 12: 632-647, 2016.

13. Olzmann JA, Li L, Chudaev MV, Chen J, Perez FA, Palmiter RD and Chin LS: Parkin-mediated K63-linked polyubiquitination targets misfolded DJ-1 to aggresomes via binding to HDAC6. J Cell Biol 178: 1025-1038, 2007.

14. Waxman EA, Covy JP, Bukh I, Li X, Dawson TM and Giasson BI Leucine-rich repeat kinase 2 expression leads to aggresome formation that is not associated with alpha-synuclein inclusions. J Neuropathol Exp Neurol 68: 785-796, 2009.

15. McLean PJ, Ribich S and Hyman BT: Subcellular localization of alpha-synuclein in primary neuronal cultures: Effect of missense mutations. J Neural Transm Suppl 58: 53-63, 2000.

16. Harding HP, Novoa I, Zhang Y, Zeng H, Wek R, Schapira M and Ron D: Regulated translation initiation controls stress-induced gene expression in mammalian cells. Mol Cell 6: 1099-1108, 2000

17. Jain A, Lamark T, Sjøttem E, Larsen KB, Awuh JA, Øvervatn A, McMahon M, Hayes JD and Johansen T: p62/SQSTM1 is a target gene for transcription factor NRF2 and creates a positive feedback loop by inducing antioxidant response element-driven gene transcription. J Biol Chem 285: 22576-22591, 2010.

18. Lau A, Zheng Y, Tao S, Wang H, Whitman SA, White E and Zhang DD: Arsenic inhibits autophagic flux, activating the Nrf2-Keap1 pathway in a p62-dependent manner. Mol Cell Biol 33: 2436-2446, 2013.

19. Ichimura Y, Waguri S, Sou YS, Kageyama S, Hasegawa J, Ishimura R, Saito T, Yang Y, Kouno T, Fukutomi T, et al: Phosphorylation of p62 activates the Keap1-Nrf2 pathway during selective autophagy. Mol Cell 51: 618-631, 2013.

20. Komatsu M, Kurokawa H, Waguri S, Taguchi K, Kobayashi A, Ichimura Y, Sou YS, Ueno I, Sakamoto A, Tong KI, et al: The selective autophagy substrate p62 activates the stress responsive transcription factor Nrf2 through inactivation of Keap1. Nat Cell Biol 12: 213-223, 2010

21. Ran FA, Hsu PD, Wright J, Agarwala V, Scott DA and Zhang F: Genome engineering using the CRISPR-Cas9 system. Nat Protoc 8: 2281-2308, 2013

22. Livak KJ and Schmittgen TD: Analysis of relative gene expression data using real-time quantitative PCR and the 2(-Delta Delta C(T)) method. Methods 25: 402-408, 2001.

23. Pickart CM and Fushman D: Polyubiquitin chains: Polymeric protein signals. Curr Opin Chem Biol 8: 610-616, 2004.

24. Zhang C, Gao J, Li M, Deng Y and Jiang C: p38ס MAPK regulates aggresome biogenesis by phosphorylating SQSTM1 in response to proteasomal stress. J Cell Sci 131: 131, 2018.

25. Hao R, Nanduri P, Rao Y, Panichelli RS, Ito A, Yoshida M and Yao TP: Proteasomes activate aggresome disassembly and clearance by producing unanchored ubiquitin chains. Mol Cell 51: 819-828, 2013.

26. Mekhail K, Khacho M, Carrigan A, Hache RR, Gunaratnam L and Lee S: Regulation of ubiquitin ligase dynamics by the nucleolus. J Cell Biol 170: 733-744, 2005.

27. Cui T, Lai Y, Janicki JS and Wang X: Nuclear factor erythroid-2 related factor 2 ( Nrf2)-mediated protein quality control in cardiomyocytes. Front Biosci 21: 192-202, 2016.

28. Hochmuth CE, Biteau B, Bohmann D and Jasper H: Redox regulation by Keap1 and Nrf2 controls intestinal stem cell proliferation in Drosophila. Cell Stem Cell 8: 188-199, 2011.
29. Kovac S, Angelova PR, Holmström KM, Zhang Y Dinkova-Kostova AT and Abramov AY: Nrf2 regulates ROS production by mitochondria and NADPH oxidase. Biochim Biophys Acta 1850: 794-801, 2015.

30. Arakawa $\mathrm{M}$ and Ito $\mathrm{Y}$ : $\mathrm{N}$-acetylcysteine and neurodegenerative diseases: Basic and clinical pharmacology. Cerebellum 6: 308-314, 2007.

31. Sheng XJ, Tu HJ, Chien WL, Kang KH, Lu DH, Liou HH, Lee MJ and Fu WM: Antagonism of proteasome inhibitor-induced heme oxygenase- 1 expression by PINK 1 mutation. PLoS One 12 : e0183076, 2017.

32. Kim D, Kim SH and Li GC: Proteasome inhibitors MG132 and lactacystin hyperphosphorylate HSF1 and induce hsp70 and hsp27 expression. Biochem Biophys Res Commun 254: 264-268, 1999.

33. Vadlamudi RK and Shin J: Genomic structure and promoter analysis of the p62 gene encoding a non-proteasomal multiubiquitin chain binding protein. FEBS Lett 435: 138-142, 1998

34. Lim J, Lachenmayer ML, Wu S, Liu W, Kundu M, Wang R, Komatsu M, Oh YJ, Zhao Y and Yue Z: Proteotoxic stress induces phosphorylation of p62/SQSTM1 by ULK1 to regulate selective autophagic clearance of protein aggregates. PLoS Genet 11: e1004987, 2015

35. Matsumoto G, Wada K, Okuno M, Kurosawa M and Nukina N: Serine 403 phosphorylation of p62/SQSTM1 regulates selective autophagic clearance of ubiquitinated proteins. Mol Cell 44 279-289, 2011

36. Du ZX, Yan Y, Zhang HY, Liu BQ, Gao YY, Niu XF, Meng X and Wang HQ: Proteasome inhibition induces a p38 MAPK pathway-dependent antiapoptotic program via Nrf2 in thyroid cancer cells. J Clin Endocrinol Metab 96: E763-E771, 2011.

37. Kopito RR: Aggresomes, inclusion bodies and protein aggregation. Trends Cell Biol 10: 524-530, 2000

38. Szebenyi G, Wigley WC, Hall B, Didier A, Yu M, Thomas P and Krämer H: Hook2 contributes to aggresome formation. BMC Cell Biol 8: 19, 2007.

39. Bolhuis S and Richter-Landsberg C: Effect of proteasome inhibition by MG-132 on HSP27 oligomerization, phosphorylation, and aggresome formation in the OLN-93 oligodendroglia cell line. J Neurochem 114: 960-971, 2010.

40. Meriin AB, Zaarur N and Sherman MY: Association of translation factor eEF1A with defective ribosomal products generates a signal for aggresome formation. J Cell Sci 125: 2665-2674, 2012.

41. Hyttinen JM, Amadio M, Viiri J, Pascale A, Salminen A and Kaarniranta K: Clearance of misfolded and aggregated proteins by aggrephagy and implications for aggregation diseases. Ageing Res Rev 18: 16-28, 2014.

42. Lamark T and Johansen T: Aggrephagy: Selective disposal of protein aggregates by macroautophagy. Int J Cell Biol 2012: 736905, 2012.

43. Takalo M, Salminen A, Soininen H, Hiltunen M and Haapasalo A Protein aggregation and degradation mechanisms in neurodegenerative diseases. Am J Neurodegener Dis 2: 1-14, 2013.

44. Brüning A and Jückstock J: Misfolded proteins: From little villains to little helpers in the fight against cancer. Front Oncol 5: 47, 2015.

45. Park J, Park Y, Ryu I, Choi MH, Lee HJ, Oh N, Kim K, Kim KM, Choe J, Lee C, et al: Misfolded polypeptides are selectively recognized and transported toward aggresomes by a CED complex. Nat Commun 8: 15730, 2017.

46. Liu B and Qian SB: Translational reprogramming in cellular stress response. Wiley Interdiscip Rev RNA 5: 301-315, 2014

47. Sonenberg N and Hinnebusch AG: Regulation of translation initiation in eukaryotes: Mechanisms and biological targets. Cell 136: 731-745, 2009

48. Espinosa-Diez C, Miguel V, Mennerich D, Kietzmann T, Sánchez-Pérez P, Cadenas S and Lamas S: Antioxidant responses and cellular adjustments to oxidative stress. Redox Biol 6: 183-197, 2015.

49. Baird L and Dinkova-Kostova AT: The cytoprotective role of the Keap1-Nrf2 pathway. Arch Toxicol 85: 241-272, 2011.

50. McMahon M, Thomas N, Itoh K, Yamamoto M and Hayes JD: Redox-regulated turnover of Nrf2 is determined by at least two separate protein domains, the redox-sensitive Neh2 degron and the redox-insensitive Neh6 degron. J Biol Chem 279: 31556-31567, 2004.

51. Nguyen T, Sherratt PJ, Huang HC, Yang CS and Pickett CB: Increased protein stability as a mechanism that enhances Nrf2-mediated transcriptional activation of the antioxidant response element. Degradation of Nrf2 by the $26 \mathrm{~S}$ proteasome. J Biol Chem 278: 4536-4541, 2003 
52. Itoh K, Wakabayashi N, Katoh Y, Ishii T, O'Connor T and Yamamoto $\mathrm{M}$ : Keap1 regulates both cytoplasmic-nuclear shuttling and degradation of Nrf2 in response to electrophiles. Genes Cells 8: 379-391, 2003.

53. Furukawa $M$ and Xiong Y: BTB protein Keap1 targets antioxidant transcription factor Nrf2 for ubiquitination by the Cullin 3-Roc1 ligase. Mol Cell Biol 25: 162-171, 2005.

54. Holmström KM, Baird L, Zhang Y, Hargreaves I, Chalasani A, Land JM, Stanyer L, Yamamoto M, Dinkova-Kostova AT and Abramov AY: Nrf2 impacts cellular bioenergetics by controlling substrate availability for mitochondrial respiration. Biol Open 2: 761-770, 2013

55. Pilecka I, Sadowski L, Kalaidzidis Y and Miaczynska M: Recruitment of APPL1 to ubiquitin-rich aggresomes in response to proteasomal impairment. Exp Cell Res 317: 1093-1107, 2011.

56. Salemi LM, Almawi AW, Lefebvre KJ and Schild-Poulter C: Aggresome formation is regulated by RanBPM through an interaction with HDAC6. Biol Open 3: 418-430, 2014

57. Dron M, Dandoy-Dron F, Farooq Salamat MK and Laude H: Proteasome inhibitors promote the sequestration of PrPSc into aggresomes within the cytosol of prion-infected CAD neuronal cells. J Gen Virol 90: 2050-2060, 2009.

58. Beaudoin S, Goggin K, Bissonnette C, Grenier C and Roucou X: Aggresomes do not represent a general cellular response to protein misfolding in mammalian cells. BMC Cell Biol 9: 59, 2008.

59. Dantuma NP and Bott LC: The ubiquitin-proteasome system in neurodegenerative diseases: Precipitating factor, yet part of the solution. Front Mol Neurosci 7: 70, 2014.
60. Cummings CJ, Mancini MA, Antalffy B, DeFranco DB, Orr HT and Zoghbi HY: Chaperone suppression of aggregation and altered subcellular proteasome localization imply protein misfolding in SCA1. Nat Genet 19: 148-154, 1998.

61. Arrasate M, Mitra S, Schweitzer ES, Segal MR and Finkbeiner S: Inclusion body formation reduces levels of mutant huntingtin and the risk of neuronal death. Nature 431: 805-810, 2004.

62. Cummings CJ, Reinstein E, Sun Y, Antalffy B, Jiang Y, Ciechanover A, Orr HT, Beaudet AL and Zoghbi HY: Mutation of the E6-AP ubiquitin ligase reduces nuclear inclusion frequency while accelerating polyglutamine-induced pathology in SCA1 mice. Neuron 24: 879-892, 1999.

63. Gandhi J, Antonelli AC, Afridi A, Vatsia S, Joshi G, Romanov V, Murray IV and Khan SA: Protein misfolding and aggregation in neurodegenerative diseases: A review of pathogeneses, novel detection strategies, and potential therapeutics. Rev Neurosci 30: 339-358, 2019. International (CC BY-NC-ND 4.0) License. 